\title{
Appreciating Beauty in Prosperous Tang Dynasty from the Fair Lady Portrayal of Tang
}

\author{
Yuan Wang \\ Eastern International Art College \\ Zhengzhou University of Light Industry \\ Zhengzhou, China
}

\begin{abstract}
Ancient Chinese fair lady portrayal represents the peak of Chinese figure painting. The magnificent "Beauties of Prosperous Tang" leaves deep impression on Chinese and the world's people's minds. This has indispensable relation with Tang's politics and science, social tendency, ideology as well as aesthetic taste of the ruler. The special aesthetic perception of Tang Dynasty develops a unique style among the long history. It is undoubtedly valuable of studying ancient Chinese fair lady portrayal of prosperous Tang Dynasty to figure out Tang's aesthetic perception.
\end{abstract}

Keywords-Ancient Chinese fair lady portrayal; aesthetic perception; aesthetics in prosperous Tang

\section{INTRODUCTION}

Chinese artist spare not efforts to delineate female beauty with a wide variety of techniques they master. No matter graceful, mulberry picking or dancing beauties painted on bronze ware from Spring and Autumn and Warring States Period, or goddess Luoshen with surpassingly beautiful appearance who flies swiftly as a frighted heartrending swan from Wei Jin and North and Southern Dynasties, all leave unforgettable impressions on people's heart. Ji Xianlin who studied Chinese ancient civilization once even expressed that Chinese have valued feminine beauty since the ancient times. While among numerous paintings for ancient Chinese fair lady, Tang figure painter Zhang Xuan and Zhou Fang are undoubtedly important ones with particular status. Many of their lively portrayals incisively and vividly reveal Tang people's aesthetic tastes. Those ladies either wearing man's clothes or riding on horse back, or others looking toward distant places besides the fence or sparing toils and sweat in working, are all emerging in strong and bunny figures. These scenes reflected Tang people's special aesthetic tendency. French philosopher Taine (Hippolyte Adolphe Taine, French philosopher from 1828 to 1893.) held that creation of a work depends on spirit of the time and surrounding customs. As product of the time, portrayal of ancient Chinese fair lady is bound to express style and feature of Tang and verify the prevailing social custom of chasing for grand and magnificent style.

\section{Prosperous SocIETy CREATES SPECIAL BEAUTY IN TANG DYNASTY}

In traditional Chinese paintings for fair ladies done by Zhang Xuan and Zhou Fang, what frequently appears is that the delicate depict for cloth. Yet these luxuriant clothes are so surprising that they are looming veils hanging on bright and tender skin, and thus highlight female character of feminine and charming. Meanwhile, Hu clothing, a kind of clothes that western Chinese wears, that is dressed so naturally that it shows Tang female's nature of breaking away from any kind of constraint. Beauty is a weak quality here comparing to strong. Extensive female beauty is reinforced when ladies wear masculine clothes pretending to be man. Girls can also be valiant and heroic and at the same time be beautiful. And only prosperous Tang could bring this scene.

Politics and economics are highly developed during Tang Dynasty, and this period can be regarded as the peak of Chinese cultural and artistic flourishing. Especially during the most developed period of Tang, people all live and work in peace and contentment, and enjoy their lives under loose political environment, thriving economy and compatible culture that blend Chinese, western and even the whole world's culture. The then capital city Chang'an was the most flourishing, the richest and the most civilized place in the world, and this city is the yearning place of all people. A foreign monk from the western world came to China for studying once wrote that how I wish I was born in China and thus he could have the fortune to see Mount Wutai (one of the four most famous Buddhist Mountains of China.) everyday. And Du Fu eulogized in Memories of the Past that "recalling those years of peace and prosperity time of Tang that is called Kaiyuan Shengshi, even in small counties there are thousands of households living there. Recent consecutive years have witnessed the agricultural bumper harvest, and both private and national granaries are filled with grains and cereals. Politics situation was stable and people are spending affluent lives. No worries should be spared to watch out for villains and no attention should be paid to choose the right day to go out, because it is completely not necessary to do so." Satisfaction for life and introduction and absorbing of the foreign culture bring to the creation and renovation of breaking the restrained tradition without any reluctant in brave manner. This is the social atmosphere and ideological basis of the so called artistic "Voice of the Flourishing Tang Dynasty". If art in Qin and 
Han Dynasty was the human conquering and transforming of the natural environment, and Wei Jin and Liuchao Dynasty art was the decadent music popularized among upper class which emphasis the inner and spirit of each character, then art in Tang Dynasty is the affirmation and feeling toward human reality, and the vision plus dedication for the future.

\section{CONFUCIANISM, TAOISM AND BUDDHISM FLOURISHED}

During Sui and Tang Dynasties, the tripartite confrontation of Confucianism, Taoism and Buddhism has been formed and the communication between these three schools was frequent. It becomes a trend for young aristocrats to study and discuss theory and doctrine of three believes. After consulting to Epitaph of Tang Cuikai and other documents, Prof. Dong Guodong from Wuhan University holds that studying Confucianism, Indian Buddhism and Taoism was the general trend for Sui and Tang people as well as their family. Whereas all these are based on Confucian ideology, which is serving the country.

Chinese artists who value morality and ethics would always endow the subjects in their painting a certain extent of great morality on the artistic characters in their creations that are based on the reality but actually more than just real life according to portrait of fair ladies of Tang. The beauty consciousness of "tender and honest" held by Confucianism is the dominated aesthetics during Tang and even the whole feudal society. The images of imperial fair ladies with tender expressions, seemingly dynamic and smooth curved figures are just the embodiment of such perceptions. These ladies are wealthy and carefree, comfortable and luxurious, and at the same time they reveal the disdain for fame and the desire for nature, their willingness to lead quiet and peaceful lives. All above reveals the rational and reserved side of their emotion.

Fair ladies portrayals in Tang Dynasty are also the valuable product of ritual civilization spirit of Confucianism, for which its essence is pursuing for order and harmony. The plump facial profile, well-developed robust posture, magnificent lines and splendid color are all presentations of the combination for strong and drifting beauty. Besides, it bears graceful and noble spirit. It is undoubtedly that the artists put much of their own thoughts and feelings for life into their works, so the paintings show their praise for Tang people's generous vitality. These are also the product of the highly development of aesthetics.

On the other hand, in portrait of the fair lady of Tang, people could have a glance of the exquisite makeup of Tang females. They put on flower-shaped patterns on their forehead and cheek, use grand and delicate hairpin on the hair, and wear complicated decorations. All these manifests the crazy pursuit of Tang female for beauty, this is widely accepted by the society and. The inclusiveness of Tang aesthetics is also embodied.

\section{REAL LifE CREATES BEAUTY}

Tang is a dynasty of splendid and grand spirit. Social attitude and status of female are believed to be rather positive. This is scarcely the case in feudal society, for which rules and regulations are important. For example, people in Tang
Dynasty discarded the traditional value for "three inches foot" like Pan Jinlian (a female character in a famous Chinese literature Jin Pingmei,) does, instead they favor healthy and normal sized foot, which means women can change their lifestyle of staying home permanently. They went out and embrace the wider space for living. The criteria of "ignorance is the most previous value of a woman" that is no longer effective for evaluating female. Value for Tang and Song poems brings more opportunities and power for women to study. This in turn lifts the spiritual consciousness of female in Tang to a brand new level. This possibly accounts for the fact that the one and only female emperor appeared in Tang Dynasty. Although litterateurs after Tang have wrote harsh words in their works to criticize this female emperor, we can hardly find any negatives words about her in Tang works.

The society endows higher social status for women and provides possibilities for them to take part in extensive outdoor activities, and hence a trend is formed afterward. Drawing of Guo State empress Spring Outing and Sight Seeing shows sisters of Yang Yuhuan, one is the empress of Qin State and the other is the empress of Guo State, dressing magnificent gown and riding horses as they are on an outdoor trip. Two married women ride horses on the street in public without any intention to avoid public attention, people would wander how could they be so daring and who would give them the courage to act like this. Is it just for they are the ones who live in Emperor Xuanzong's romance personal life? The answer seems more than that. The reason of the acceptation of ordinary people is more persuasive than the former reason. Painters of Tang Dynasty who draws the beautiful women and imperial maid portray sights they see on the basis of their own feeling for the society. This is what the incomparable era, prosperous Tang Dynasty, give to people the aesthetic taste and interest. And what they draw becomes the dominating feature of beautiful female portrayal of Tang.

The social atmosphere of advocating "vigorous beauty" also influences the formation of Tang aesthetics. According to recording of paper documents, there are many different sports activities for women to participate in different seasonal period during the whole year. Among which, what are competed today such as football, archery, boat racing and equestrianism are all included. Women of present age would be surprised to learn how abundant the activities Tang females take part in. It is hard to imagine Zhao Feiyan (a beloved concubine of an emperor in Han Dynasty) riding on a horse and playing polo. Thus it is essential to be strong for women in Tang Dynasty in order to accomplish such sports activities. Artistic archaeologists Chang Renxia once said that in fresco finished in initial stage of Tang, most women are robust and strong, this is the aesthetic perception of that time.

\section{Aesthetic Taste of the Authority Helps Form LUXURY BEAUTY OF TANG DYNASTY}

Art of each and every dynasty has something to do with ruler of temporal time. Feudal system since the Qin and Han Dynasty has been emphasized the importance of centralization, and this was mainly manifested in the construction of some cultural and art centers, which have not only led the art trend and sponsored art activities, they also formulated art criteria. 
These center themselves can be regarded as a splendid epic. Quite a few painters in Liuchao and Sui Dynasty, who are experts in traditional Chinese painting of beautiful woman portrayal, choose this subject to reflect the ordinary taste for beauty. Digging into their traditional, it is easy to discover that their choices are related closely to pattern of imperial portraits in Han Dynasty. Graceful concubines in pictures drew by imperial painters decide whether they would be favored by the emperor and thus decide their fates. In Tang Dynasty, portrayals of concubine are still required in imperial court. As the political status of painters improved, they put their emphasis on reflecting aesthetic fashion of the age when they draw this kind of painting.

Words in Xuanhe Portrayal Description put that most female painters in Zhou Fang's works are with plump and strong figures. Tang Hou in Yuan Dynasty said that Zhou Fang is an expert of drawing aristocrat figures on trip and portrait. Fair ladies in his works are with dazzling glamour and strong body with rich temperament. Their reviews show that portrayals in Zhou Fang's works are mainly upper class ladies. For his family was one of the aristocrats and he frequently social with authorities and officers who are all upper levels, this supreme social circle and continual traveling and banqueting finally give rise to their plump figures. In the meanwhile, regarding plump as the most nice-looking figure is also the social trend of that time. Dong Guangchuan wrote a Q\&A conversation in Anzheng Tu that "once I was asked whether it is the painter's own interest to draw strong and thick figures and show their skin more than body curve, I answered that this is the unavoidable fashion in Tang Dynasty. I always heard that Taizhen empress, who is also called Yang Yuhuan, has surpassing fine skin and strong figure, and this is also the case in paintings which can be seen today. Han Gong said that curved eyebrows and mellow cheeks are fancied by Tang people who promote the beauty of strong and plump. Zhou Fang is the one who lives in that era and know the trend, so he draws in this way." It shows that fashion trend of a time is decided by real life of people. Due to Fang's superior family background, his frequently visits to high officials' mansions and his social life with the upper class, this easy kind of lifestyle makes it easy to gain weight. In addition, Imperial concubine Yang Yuhuan was the apple of emperor's eye, her plump figure becomes beauty standard of women at that time. When this aesthetic value is reflected on art works, the vigorous and fleshy shape is the style of the era. But for the personal legend of Emperor Xuanzong of Tang or the advocate of imperial artists, we can hardly imagine if there would ever exists the imperial maid figure of "gorgeous in a plump manner".

\section{INFLUENCES OF TANG LITERATURE WORKS TOWARD AESTHETICS}

Female pursuit for beauty would ultimately be resolved into their catering for people who appreciate them, just as the sayings "A girl will doll herself up for him who loves her" and "fair lady with gorgeous appearance would be a perfect match for an integrity gentleman" put it. It is undoubted that the Tang literati is the group of people who first appreciated and advocated female beauty. Their tastes for female appearances had unquestionably become woman's impetus for their chasing of beauty.

Litterateurs in Tang Dynasty not only enjoyed the fairness of ladies in their ordinary lives, they also recorded these features of loveliness intensively in their literature works. A famous poem written by Du Fu wrote in his work Appreciating Master Gongsun's Disciple Doing Sword Dance and Writing a Poem for Her that "Once upon a time, a fair lady whose first name is Gongsun, would make a splash every time when she does sword dance. The number of audiences is so large that they form array like mountains, their facial expressions are consistently changing as the story in her dance varies. It seems the haven and earth is also touched by her". As a female dancer, she plays sword rather excellent and even better than man does, her performances are grand and magnificent, vigorous and swift with elegant demeanor. In Zhang Ji's poem Written on HanShi Day Banquet, the day before Chinese Tomb Sweeping day, which represents the coming of spring, the poet described that "Beauty on their horses chasing flying balls in front of the palace", and also Poetry for Imperial Palace written by Wang Jian, "imperial maids all put on makeup after hearing that they would accompany the emperor go hunting, they try to soot the arrow with the bow. Before departing, emperor rewards them with royal wine, they bent their knees to express gratefulness to the king imitating how men would do it". These words vividly described bright and valiant images of women when they participate in sports activities. As an era of male dominated society, Tang Dynasty people recognize and appreciate robust as an important female feature. This thought positively inspires female pursue for energetic and plump figure, and this consequently forms the Tang aesthetic value toward female.

\section{CONCLUSION}

The trend of art development can be always traced directly to the politics, economy and culture of that period. It is an indispensable part of social ideology. Plump figure of female in Tang Dynasty was mainly due to affluent economy and free social environment of that era, and also the authority advocated this trend. The participation and prevalence of outdoor sports as well as the influence of literature works also contributed to this fact. Thus the creation of Plump and Resplendent Beauty by Zhang Xuan and Zhou Fang is not only an inevitable result of social development, also the product of Tang society advanced development and a visualized embodiment of Tang people aesthetic value.

\section{REFERENCES}

[1] Ye Lang. Outline of the History of Chinese Aesthetics[M]. Shanghai: Shanghai People's Publishing House, 2001.

[2] Hong Zaixin. Chinese Art History[M]. Hangzhou: China Academy of Fine Arts Publishing House, 2000.

[3] Jia Tao. Tutorial of Aesthetics[M]. Beijing: China Environmental Science Press, 2006.

[4] Zhang Qian. Introduction of Arts and Aesthetics [M.] Beijing: Peking University Press, 2008

[5] Li Zehou. Three Books of Aesthetics[M]. Tianjin: Tianjin Academy of Social Sciences Publishing House, 2008. 
[6] Wang Bomin. General History of Chinese Paintings[M]. Beijing: Living - Reading • New Knowledge Joint Publishing, 2008. 